\title{
MEXICO VISTO POR PINTORES EXTRANJEROS DEL SIGLO XIX
}

\section{P O R}

\author{
MANUEL ROMERO DE TER REROS
}

I

Fs cosa bien sabida que después de la consumación de la Independencia, $y$ durante el resto del siglo XIx, vinieron a México varios pintores extranjeros, que trasladaron al lienzo o al papel tipos, costumbres $y$ paisajes de nuestro país. No será, pues, ocioso recordar los nombres de unos cuantos de estos artistas, que quisieron dar a conocer las bellezas de nuestro suelo en otras latitudes y con lo cual se hicieron acreedores a nuestro aprecio $y$, en cierto modo, a nuestra gratitud.

II

Toca el primer lugar, en el orden cronológico, al pintoresco personaje que llevó el nombre de conde Octaviano d'Alvimar. Este aventurero francés, cuyas andanzas en México ha bosquejado Justino Fernández en el estudio que hizo del cuadro que vamos a mencionar y que forma parte actualmente de la colección de don Antonio Díaz Lombardo, cualesquiera que hayan sido sus defectos en el orden político, tuvo la virtud de ser acucioso aficionado al bello arte de la pintura. Parece que aquí, en México, ejecutó varias obras, pero la más importante fue, la que representa la 
Plaza Mayor, pintada, probablemente, en 1822. Mide el cuadro sesenta y ocho por ochenta y siete centímetros, y está ejecutado "al temple, dice Justino Fernández, aplicado con suavidad y transparencia, por lo que resulta, ante todo, su bien perfilado dibujo". Representa la monumental Plaza Mayor, en día de gala; a nuestro parecer, cuando el Emperador Agustín de Iturbide regresaba a Palacio, después de haber instituido la Orden de Guadalupe en la Colegiata. Al frente, la Catedral y el Sagrario, al fondo el Seminario y, a la derecha, la esquina de Palacio, están reproducidos con aceptable fidelidad; pero del rectángulo mismo de la Plaza, que pueblan cientos de figuras, se echan de menos, desde luego, el Parián, que en esa época aún existía, y la famosa estatua de Carlos Iv, que en esos días se hallaba cubierta con un gran globo de madera y papel. Hizo bien d'Alvimar en suprimir ambos adefesios. En cuanto al valor artístico del cuadro, dice Justino Fernández, "que lo más interesante de la pintura de d'Alvimar, es el movimiento y la precisión con que sabía dibujar personas, animales y demás detalles de la vida mexicana de principios del siglo xIX. Toda la parte inferior del cuadro está deliciosamente dispuesta y dibujados a la perfección todos sus elementos..."

\section{III}

El alemán Juan Moritz Rugendas, quien, además de pintor, ha sido considerado historiador y etnógrafo, por su enorme producción de más de cinco mil dibujos, acuarelas y óleos, de tipos, costumbres, indumentaria y paisajes, ejecutados en el Continente americano, nació en Augsburgo en el año de 1802, hijo da Juan Lorenzo Rugendas, Director que era de la Academia de Arte de aquella ciudad. Después de haber recorrido el Brasil y otras naciones, Rugendas llega a México en 1831 y permanece aquí cuatro años, durante los cuales ejecuta más de mil seiscientos dibujos, acuarelas y óleos, de toda clase de asuntos: retratos, costumbres, paisajes. Se comprenderá que no toda esta obra había de ser gran valor artístico; nos atreveríamos a decir que, en su mayoría, es de importancia más documental que estética. Sin embargo, muchos de sus cuadros, especialmente los que se refieren a la comarca veracruzana, sí son de mérito pictórico. Para que se comprenda la enorme labor de Rugendas en nuestro país, enumeraremos, siguiendo a Federico Hernández Serrano, la agrupación de los asuntos que trató: a saber, Habitantes del pás, Los criollos, Los campesinos, Los mestizos, La vida de las ciudades, Oficios 
en las pequeñas cilldades y villas, La milicia y el Estado Militar, El proletario en México, La agricultura y los campesinos, La agricultura en la altiplanicie y en las zonas tórridas, La cria de ganado.

En 1855, apareció en Alemania una obra de Christian Sartorius, cuyo título puede traducirse así: México, sus paisajes y sus tipos, ilustrada con diez y ocho litografías de cuadros de Rugendas; y cuatro años más tarde, se editó en Londres la versión inglesa de dicha obra, esta vez con láminas en acero por buenos grabadores, según los mismos dibujos originales de Rugendas.

Pero no fue sino hasta el año de 1925, cuando se conoció bien en México la obra del pintor alemán, ya que en esa fecha pudieron obte nerse para nuestro país unos treinta y siete apuntes suyos. Están éstos ejecutados al óleo sobre papel y cartón, de unos doce por diez y ocho centímetros los más pequeños, y de doble tamaño los mayores. Dice Hernández Serrano que "reflejan un conocimiento muy completo de México", y el pintor Alfredo Ramos Martínez los consideró "de gran valor artístico". Se conservan actualmente en el Museo Nacional de Historia, de Chapultepec. (Figs. 1 y 2.)

IV

El diplomático francés Barón Juan Gros, hijo del pintor de El Puente de Arcole, y otros episodios Napoleónicos, formó parte de la Legación de Francia en México de 1832 a 1834, y ocupó sus ratos de ocio en pintar no pocas vistas de nuestro país. Más tarde hizo otro tanto en el Brasil y Colombia.

Las vistas mexicanas de Gros son, casi todas, de pequeñas dimensiones y están pintadas al óleo sobre tela.

Su vista de El Valle de México está tomada, al parecer, desde los aledaños del cerro de la Estrella. En primer término, numerosas áuras parecen estar en acecho de un rebaño que descansa a la sombra de una arboleda; mientras que, en el segundo, con predominio de tonos morados, se destacan los cerros cercanos y el lago de Texcoco. A lo lejos, sobre límpido cielo azul asoman las cumbres de los volcanes. Este cuadro, por su colorido y su composición, de no estar firmado, podría atribuirse a don José María Velasco, lo que constituye su mejor elogio. (Fig. 3.)

En su El Cráter del Popocatépetl, la inmensa sima, con paredes de tintes amarillentos, se abre ante nuestros ojos inesperadamente, acostum- 
brados como estamos a asociar siempre las alturas del volcán con su extenso y perpetuo manto de nieve, la que aquí apenas se asoma en las orillas del cráter. (Fig. 4.) La nieve, en cambio, abunda en otras dos pinturas del volcán: una, en que el nevado cono se destaca sobre un cielo azul sin nubes, y otra, que representa en detalle El Pico del Fraile, montón de rocas volcánicas de color café obscuro, que contrastan con la blancura de la nieve que las rodea.

Un cuadro del Barón Gros lleva el título de El Peñón Grande, pero este cerro no aparece en él, sino otros de su vecindad; así como un pantano, continuación del lago de Texcoco, profusamente poblado de patos y gallaretas.

Los pinceles de Gros no podían haber pasado por alto el Castillo de Chapultepec; pero, al parecer, el Barón pintó este cuadro de memoria, ya que esta vista resultó en completo desacuerdo con la realidad. No carece, sin embargo, de mérito artístico.

Cuadro agradable es el de un camino, en las cercanías de San Angel, en que se ve, al fondo, el Ajusco, con su Pico del Aguila, que años más tarde habia de ser tema favorito de don José María Velasco.

En una de sus excursiones por el hoy Estado de Morelos, ejecutó el Barón Gros sendas agradables vistas de El Valle de Cuautla y de la $H a-$ cienda de Santa Clara. (Fig. 5.) Pero las obras de mayor aliento del Barón Gros, fueron indudablemente, Las Grutas de Cacahuamilpa, y El Valle ¿de México, que desarrolló en telas de mayores dimensiones que las de los anteriores. El tema que escogió Gros para su cuadro de Cacahuamilpa, fue una combinación de las cavernas llamadas "Salón del Chivo" y "Salón del Tronco de Palmera", debidos estos nombres a las estalagmitas que se suponian afectaban esas formas. Ambas peregrinas estalagmitas figuran en el cuadro de Gros, al lado izquierdo, mientras que, en el centro, sobre unas grandes rocas horizontales, a manera de mesas, están representados diversos objetos para uso de los excursionistas. Al lado, en la figura que está de frente, creemos ver el autorretrato del pintor, $y$, en el suelo, un portafolio de dibujos. En la roca, en el ángulo inferior derecho del cuadro, están escritos los nombres de las personas que acompañaron a Gros, en su excursión. Toda la composición de este cuadro está artísticamente ideada, y su ejecución nada deja que desear: las figuras, la luz y las sombras, los tintes de diversos matices de las rocas; todos los detalles, en fin, de esta pintura interpretan a maravilla una de las más estupendas obras de la naturaleza. (Fig. 6.) 
El Valle de México es una vista tomada, al parecer, desde las lomas rumbo a Contreras. Al fondo del cuadro se divisan los volcanes $y$, en segundo término, otros cerros con el lejano caserío de la ciudad a la izquierda y el perfil del Castillo de Chapultepec a la derecha. En primer término, bajo un árbol del cual cuelga un "cuero de pulque", se ve un grupo de seis figuras: un campesino de pie, y dos mujeres y tres soldados sentados en el suelo, a la vera de una mesa con vasos y cazuelas. Atrás, hacia la izquierda, una capilla parece representar la ermita que aun existe, en ruinas, en el camino de San Angel a Tlalpan; y a la derecha, se ven un maguey, varios arbustos y otra vegetación, todo de perfecto dibujo y fidelísimo acabado. En suma, este cuadro, en nuestra opinión, debe considerarse la obra maestra del Barón Juan Gros.

\section{v}

Contemporáneo del Barón Gros fue el caballero inglés Daniel Tomás Egerton, quien, desgraciadamente, después de algunos años de estancia en México, fue villanamente asesinado en Tacubaya, en compañía de su esposa, el 27 de abril de 1842. Era Egerton un excelente pintor, como lo demuestran los diversos paisajes que aquí ejecutó.

Indudablemente, su obra maestra es un gran óleo de El Valle de México, que exorna hoy uno de los salones de la Embajada inglesa en esta capital. La vista, con la ciudad al fondo, parece estar tomada desde las alturas de Tacubaya $y$, como las posteriores del mismo tema que ejecutaron Landesio, Velasco y su escuela, se halla animada con figuras y caballerias, sin que falten, por supuesto, los típicos nopales, magueyes y demás. Es cuadro de gran luminosidad, delicado colorido y excelente dibujo. (Fig. 7.)

De una excursión al Popocatépetl, que llevó a cabo en 1834, en compañía del Barón Gros produjo Egerton cinco cuadros al óleo sobre tela, de unos cincuenta por treinta centimetros, que representan sendos paisajes de aquella comarca, entre ellos una vista del cráter del volcán muy parecida a la que del mismo sitio ejecutó el pintor francés, pero más luminosa.

En la misma ocasión pintó Egerton la iglesia de Atlautla, pero se tomó la licencia de situarla casi al pie del Popocatépetl, cuando, en realidad, está bien lejos del volcán.

En 1840, durante una corta estancia en Inglaterra, publicó Egerton en Londres un portafolio de vistas mexicanas, que consiste en una serie 
de doce litografias a colores, con retoques a la acuarela, que reproducen otros tantos óleos originales, ejecutados por el pintor. Están estas litografías magistralmente ejecutadas. Acompaña a las estampas un cuaderno explicativo, cuyo texto, evidentemente de la pluma de Egerton, contiene muy peregrinas descripciones, que demuestran, cuando menos que su autor conoció de visu, los sitios que reproduce. Por cierto que las litografías y sus descripciones no siguen un orden geográfico determinado, puesto que de Puebla saltan a Zacatecas, de Guanajuato a Real del Monte y Veracruz, y de alli a Guadalajara y México, pasando por Aguascalientes. Este desorden, claro está, no tiene importancia desde el punto de vista artístico, pero pudo fácilmente evitarse.

De toda esta serie de vistas, las que nos parecen mejor logradas, sin por esto restar mérito a las demás, son las que representan la Hacienda de Barrera y la Plaza de San Diego en Guanajuato. (Figs. 8 y 9.) En aquella, reproduce Egerton el corredor de una típica casa mexicana de antaño, y ésta, de brillante colorido como las demás, las supera en la minuciosa ejecución de las numerosas figuras que pueblan la escena: los individuos y bestias, que se ven caminar y alejarse por una de las calles de la histórica ciudad, constituyen, a nuestro entender, un verdadero alarde de perspectiva. En este mercado de la Plaza de San Diego se presentan de nuevo ante nuestros ojos, tipos nacionales, como el aguador, las vendedoras y marchantas, que, si hace un siglo eran corrientes en villas y ciudades mexicanas, hoy en día han desaparecido para siempre. Otra de las vistas del portafolio, que nos parece muy bien lograda, es la del Paso del Viático, por las calles' de Aguascalientes. (Fig. 10.)

En suma, Daniel Thomas Egerton fue un pintor exquisito, que amó y supo interpretar magistralmente la incomparable belleza de nuestro suelo.

\section{$\mathbf{v}$}

En la tercera exposición de la Academia de San Carlos, celebrada en el año de 1851, el inglés Carlos Bowes presentó una vista de Guanajuato y otra de Acapulco y su bahia, pinturas que tuvimos ocasión de conocer, hace algún tiempo, en una casa de antigüedades, y que nos parecieron bien dibujadas pero de colorido un tanto opaco. En la exposición de 1852, Eduardo Pingret, francés, buen retratista al pastel, presentó varios óleos de cuadros de costumbres mexicanas, con tipos como el de El aguador, 
entre otros; y en la de 1854, Carlos Byrne, exhibió una Vista de hacienda y sendos paisajes de La Sierra Madre y Chapultepec, cuadros que no deben de haber sido superiores a los de Bowes.

VII

Pedro Gualdi, italiano de quien poco se sabe, se distinguió más que nada como litógrafo, en el conocido álbum de Los Monumentos de México, y otras estampas, en sepia y en colores, de cuadros que había ejecutado previamente al óleo, y algunos de los cuales expuso en la Academia en 1855. Bien conocidas son las vistas del exterior y del interior de la catedral de México, y del Palacio de Minería, que se conservan en el Museo Nacional de Historia, de Chapultepec, en donde puede fácilmente aquilatarse su valor artístico. Un cuadro de Gualdi, de nuestra colección, representa el Castillo de Chapultepec, y es interesante, porque demuestra el estado en que se encontraba el histórico edificio en la época de la invasión norteamericana de 1847.

vIII

Recordemos, de paso, y aunque sea solamente de nombre, a Bullock Junior, Mrs. Ward, Linati, Waldeck, Philips y demás artistas extranjeros, que, en diferentes épocas reprodujeron, en la estampa y en el grabado, aisladamente o como ilustraciones de libros, numerosos paisajes, monumentos, tipos, antigüiedades y costumbres de México, en forma a veces peregrina, como aquella estrafalaria figura de Miguel Hidalgo, de Linati, que parece, más bien, de un personaje de opera bufa.

\section{IX}

A mediados del siglo xrx pasó por México, casi inadvertido, el pintor francés León Gauthier, quien en los diversos lugares que visitó ejecutó apuntes $y$, bosquejos, en sepia y a la acuarela, algunos de los cuales, que conocimos en cierta ocasión, no nos parecieron obra de todo un artista, sino más bien de un mero aficionado. Sin embargo, sabemos que años 
después, de vuelta en París, un cuadro suyo, Arboles de México, mereció los honores de ser expuesto en el Salón de 1873.

León Gauthier solía acompañar a cada dibujo o pintura suya una nota descriptiva. Así, por ejemplo, cuando, a la madrugada siguiente de su desembrco en Veracruz, emprendió el viaje a Jalapa en una litera, acompaña al apunte respectivo estas líneas:; "La litera va tirada por dos mulas que, con su trote, le imprimen un balanceo desagradable; un muchacho maneja las mulas, mientras dos acémilas de carga llevan los equipajes. Un lancero abre la marcha; el 'patrón' la dirige y siguen de cerca seis hombres armados de sables, lanzas y carabinas. El cielo está lleno de estrellas y se oye la monótona queja de las olas. Llega el día y arroja a nuestro alrededor una luz incierta que anima a nuestra pequeña comitiva."

Al aproximarse a la Capital, nos informa Gauthier que los lagos se cubren de patos. "Para atraparlos, dice, los indios echan a flotar calabazas durante algunos días y cuando los palmípedos se han acostumbrado a verlas de cerca, un indio se pone una calabaza en la cabeza y se mete al agua entre ellos, de manera que coge los que quiere tirándolos de una pata." Y junto a dos apuntes suyos de Amecameca y sus cercanías, escribe : "El paisaje es admirable; el convento se destaca en tonos rosas sobre el fondo azul de la falda de los volcanes."

León Gauthier visitó las principales ciudades de "tierra adentro", en donde, según se sabe, pintó retratos y tomó apuntes de paisajes y costumbres mexicanas. Se ignora el paradero actual de estos frutos de su pluma y de su pincel.

\section{$\mathbf{x}$}

Pero el pintor que vio a México con más amplia y clara visión, fue el paisajista don Eugenio Landesio, quien en México formó escuela y tuvo varios excelentes discípulos, el principal de los cuales fue el esclarecido José María Velasco, superior, en opinión de muchos, a su maestro.

Recomendado por don Pelegrín Clavé, para impartir la enseñanza del paisaje en la Academia de San Carlos, que entonces dirigía el pintor catalán, llegó a México don Eugenio Landesio, a principios de 1855, y poco después empezó a cumplir con su encargo, que durante diez y nueve años había de dar ópimos frutos.

Nacido en 1810, en el pequeño pueblo de Altesano, de la Italia del norte, Landesio se había establecido en Roma, desde temprana edad, al 
DOI: http://dx.doi.org/10.22201/iie.18703062e.1959.28.668

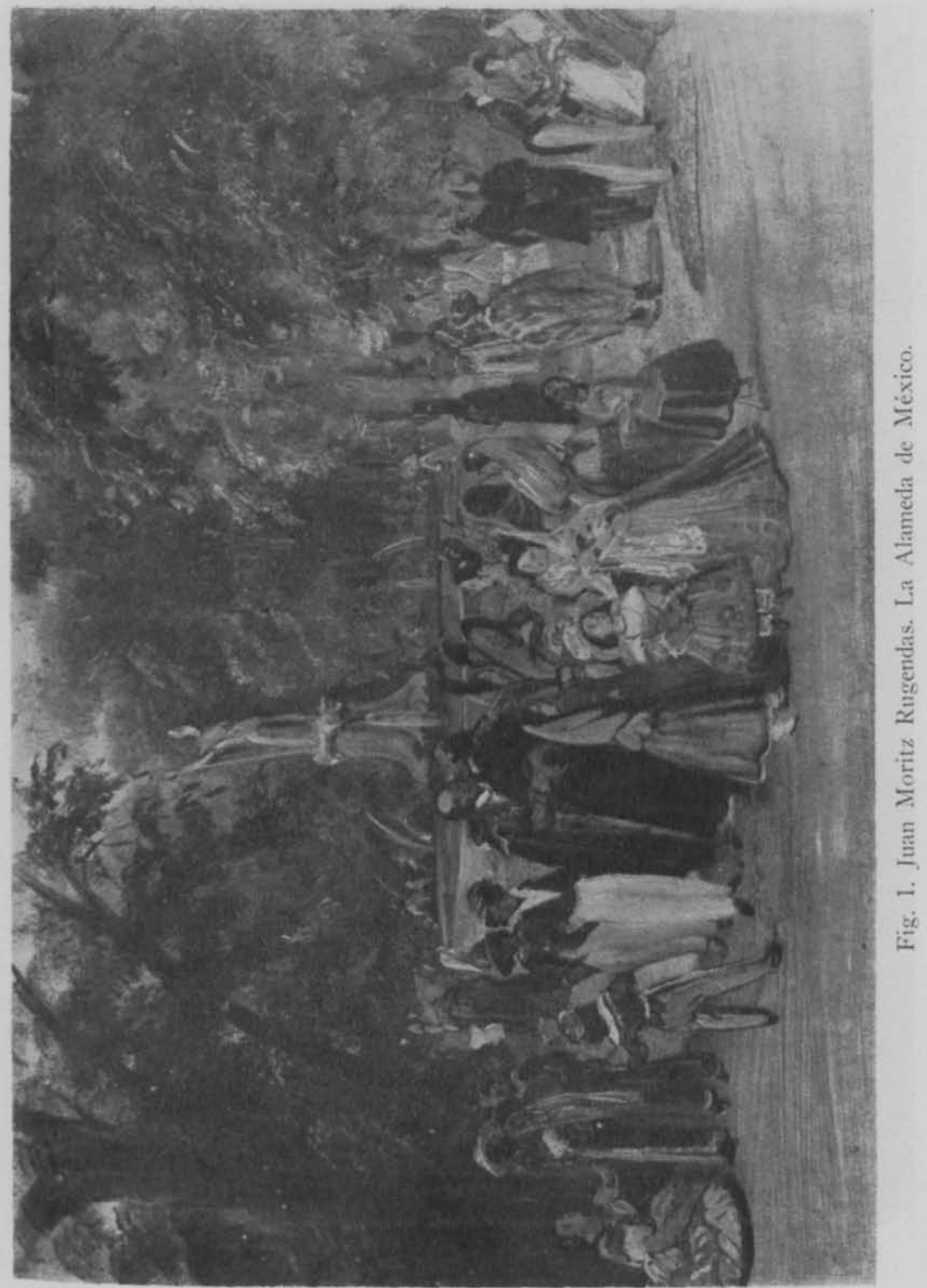


DOI: http://dx.doi.org/10.22201/iie.18703062e.1959.28.668

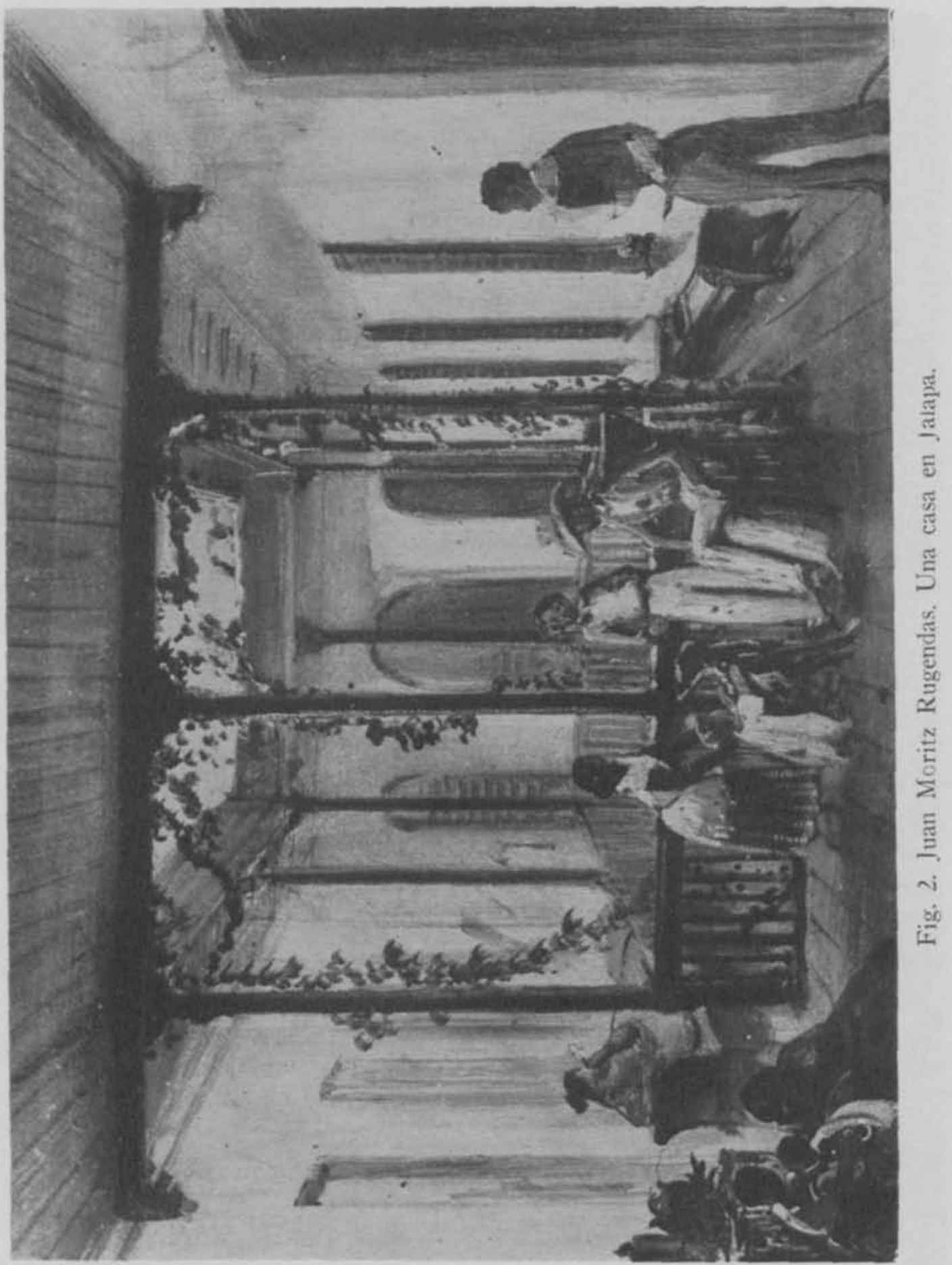


DOI: http://dx.doi.org/10.22201/iie.18703062e.1959.28.668

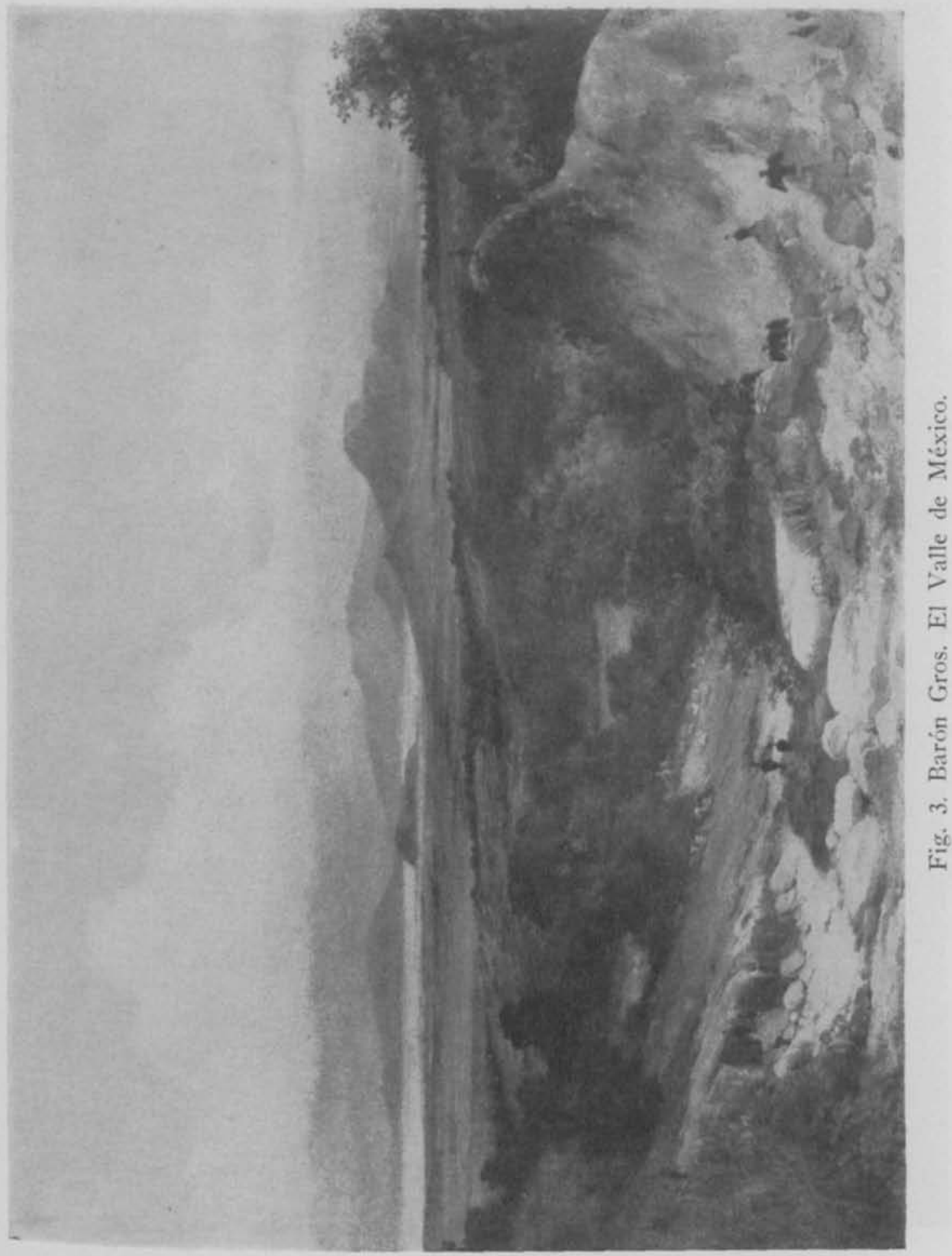


DOI: http://dx.doi.org/10.22201/iie.18703062e.1959.28.668

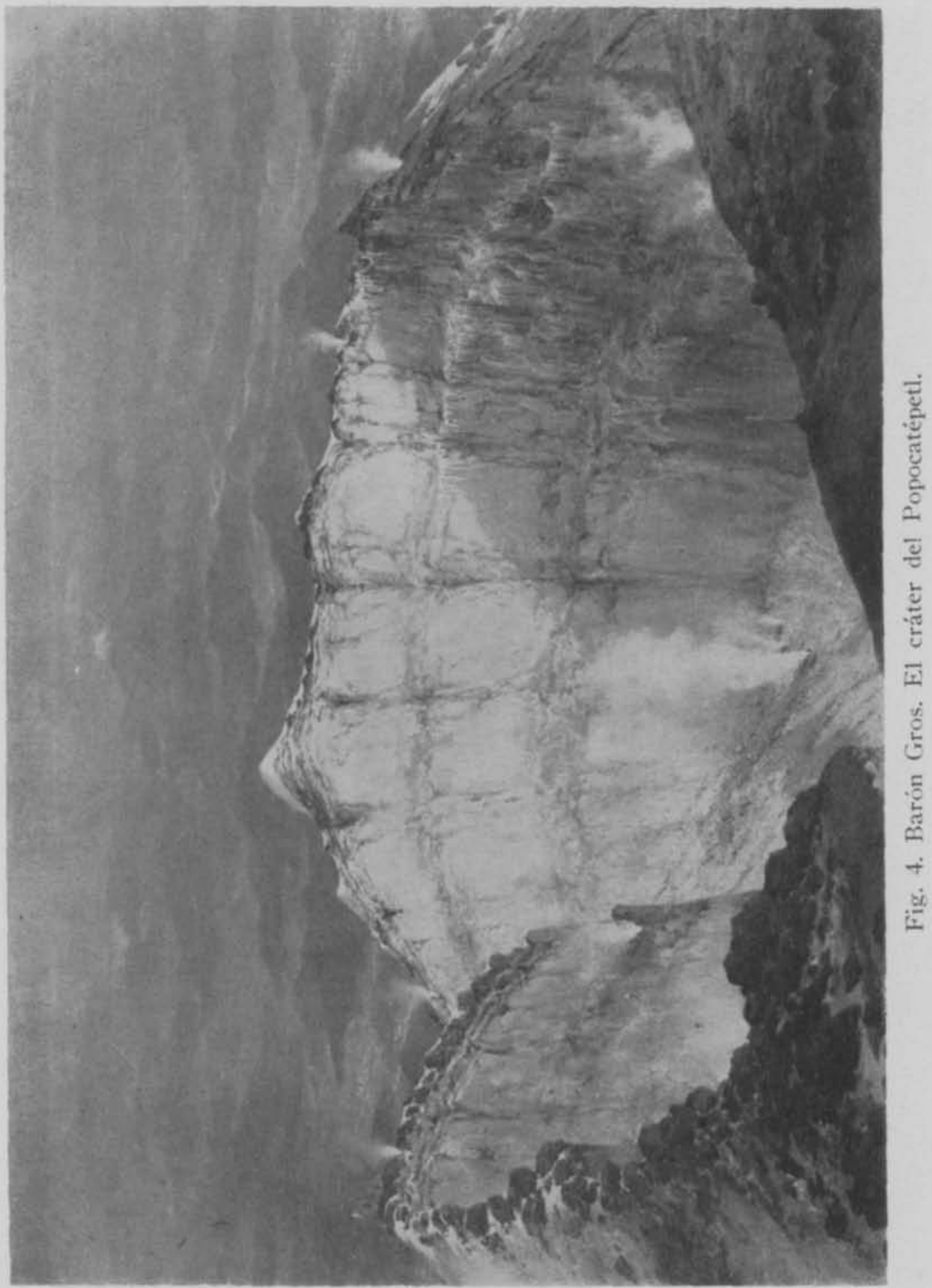


DOI: http://dx.doi.org/10.22201/iie.18703062e.1959.28.668

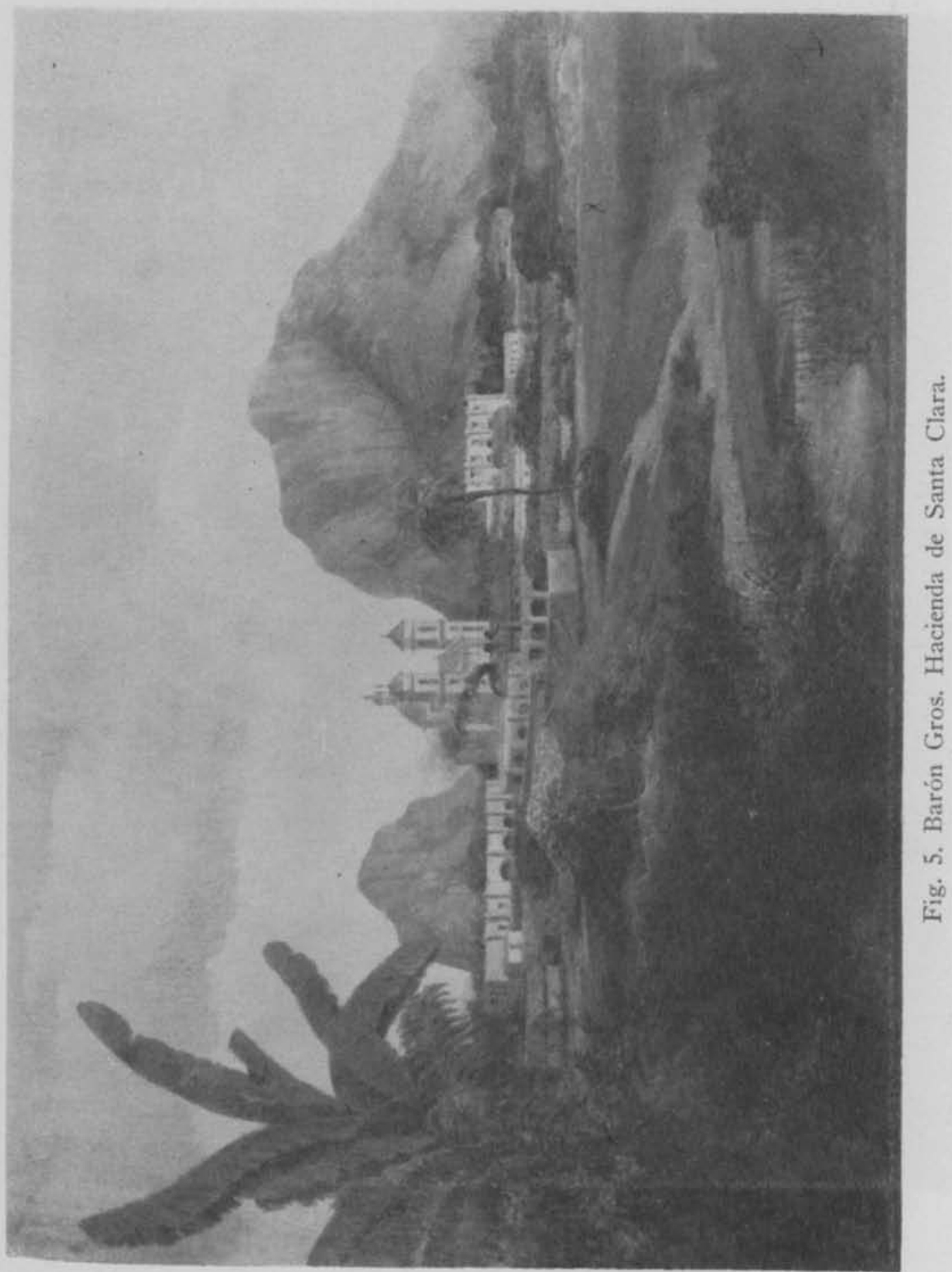


DOI: http://dx.doi.org/10.22201/iie.18703062e.1959.28.668

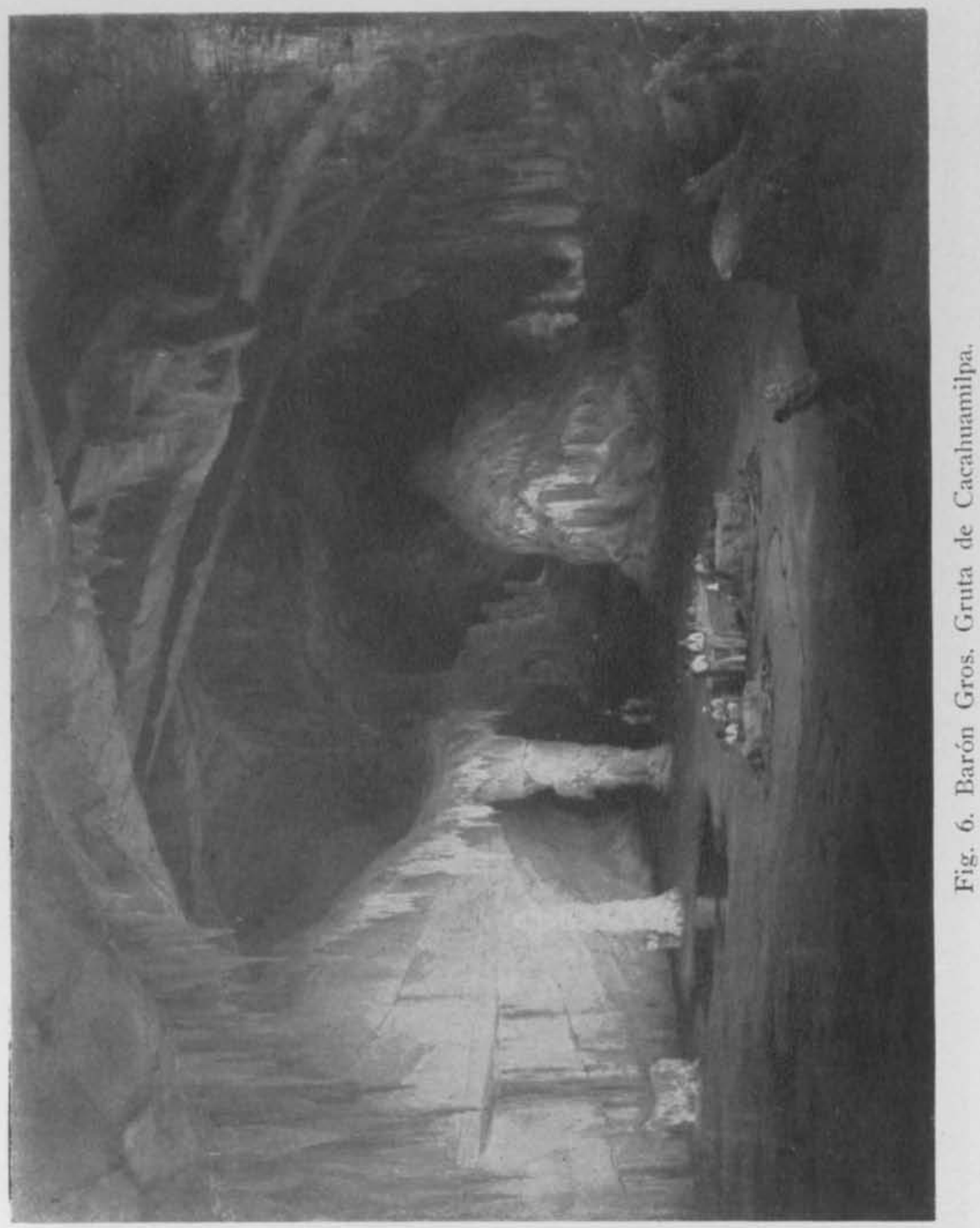




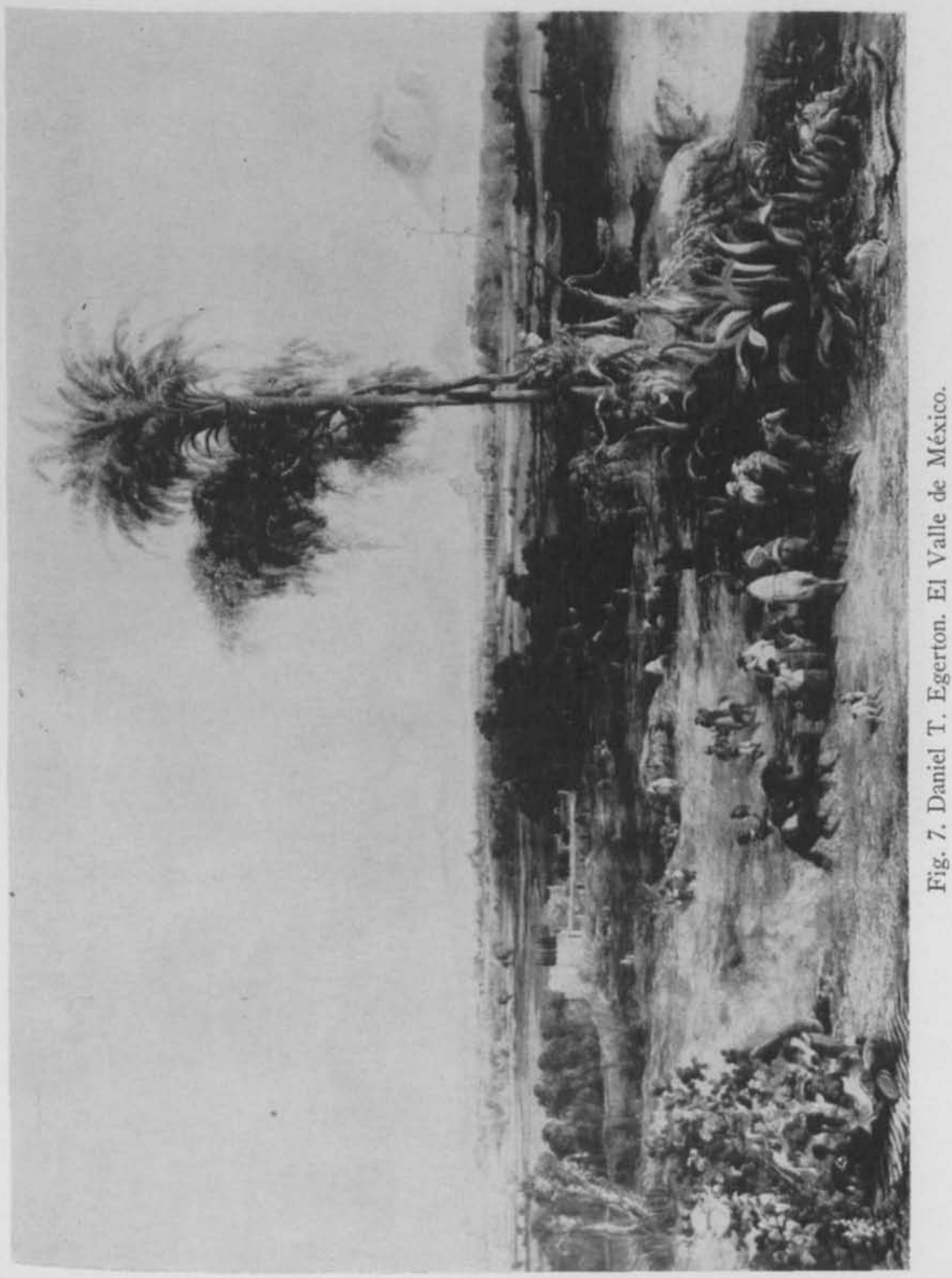


DOI: http://dx.doi.org/10.22201/iie.18703062e.1959.28.668

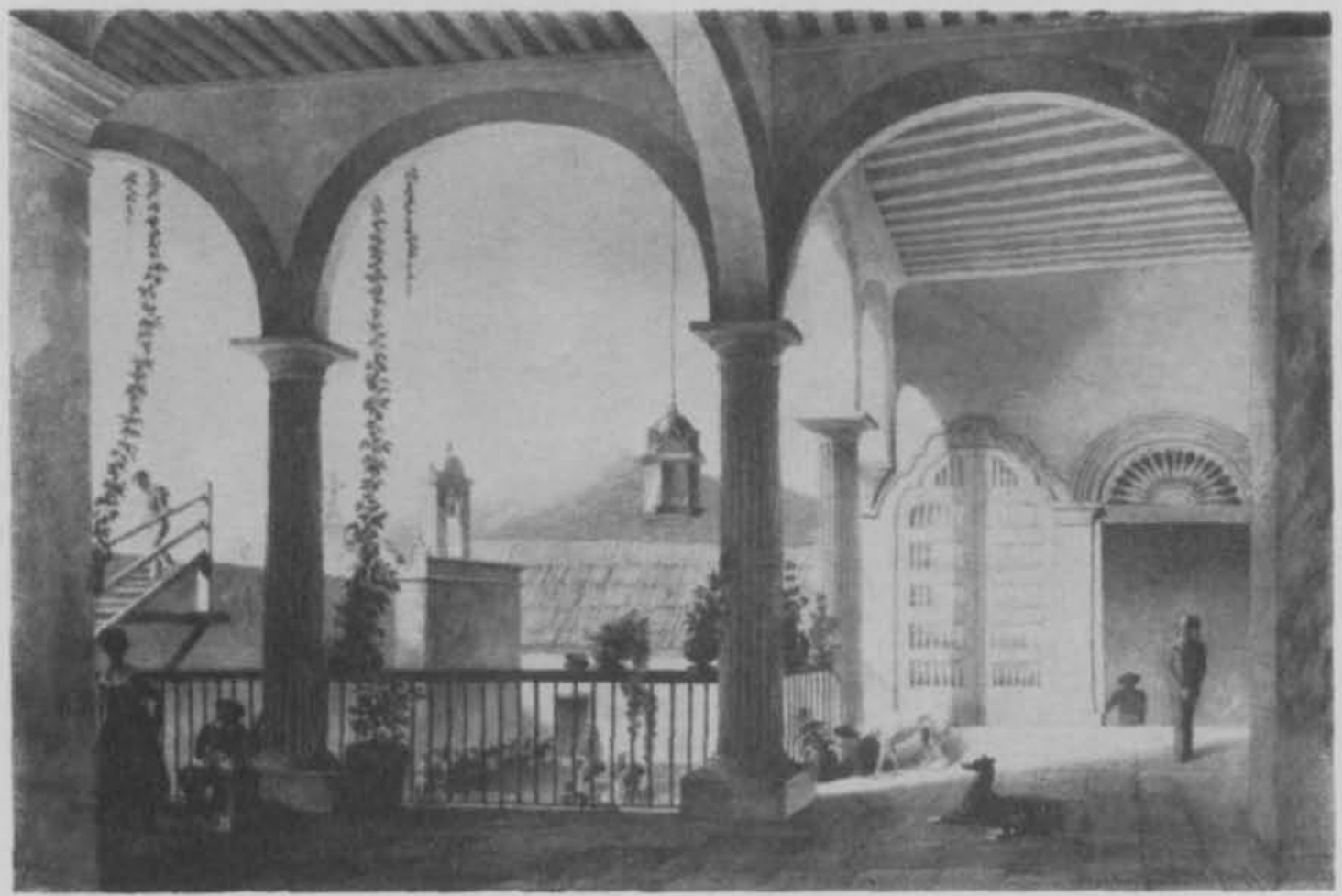

Fig. 8. Daniel T. Egerton. Hacienda de Barrera. 
DOI: http://dx.doi.org/10.22201/iie.18703062e.1959.28.668

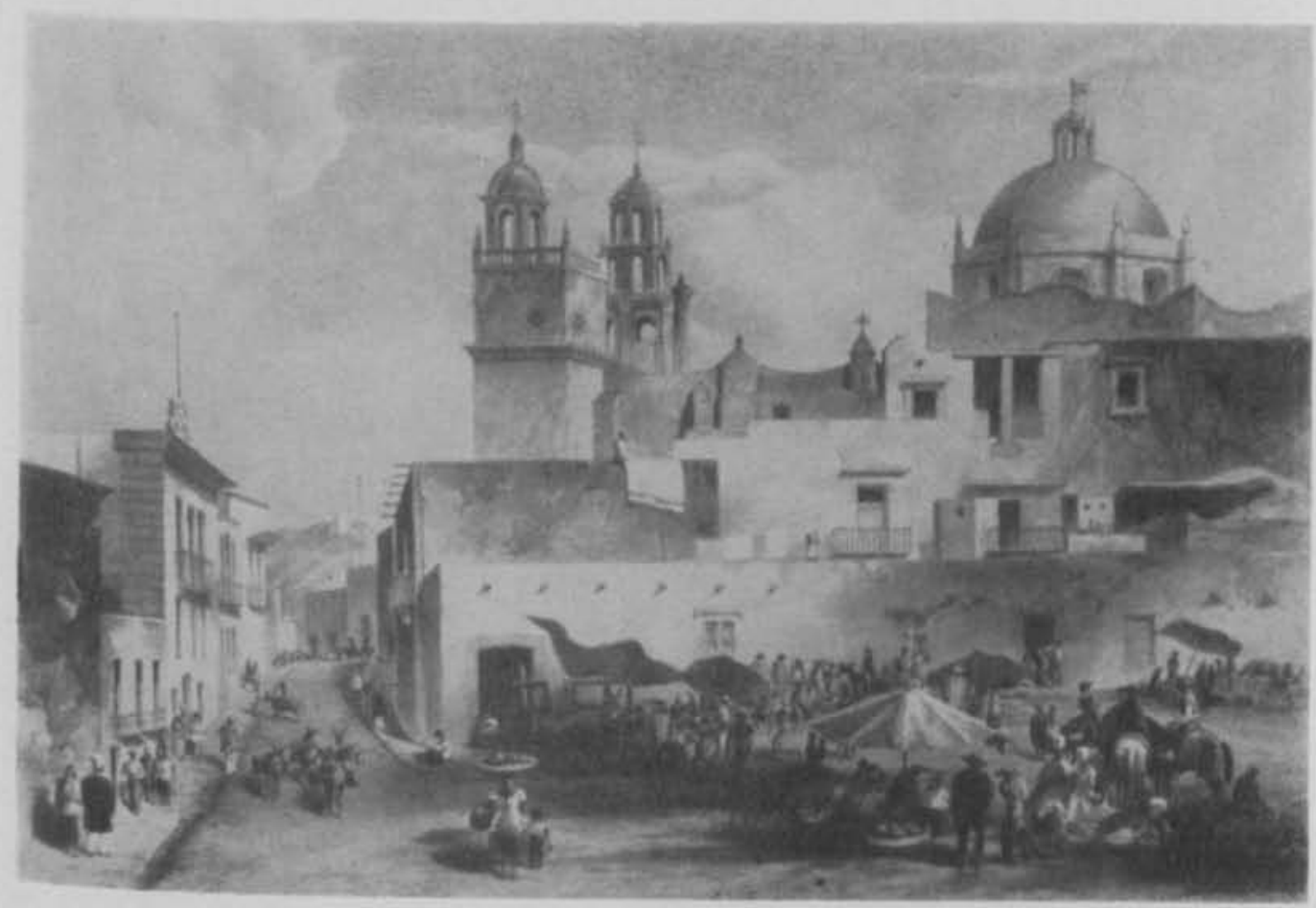

Fig. 9. Daniel T. Egerton. Plaza de San Diego, Guanajuato. 
DOI: http://dx.doi.org/10.22201/iie.18703062e.1959.28.668

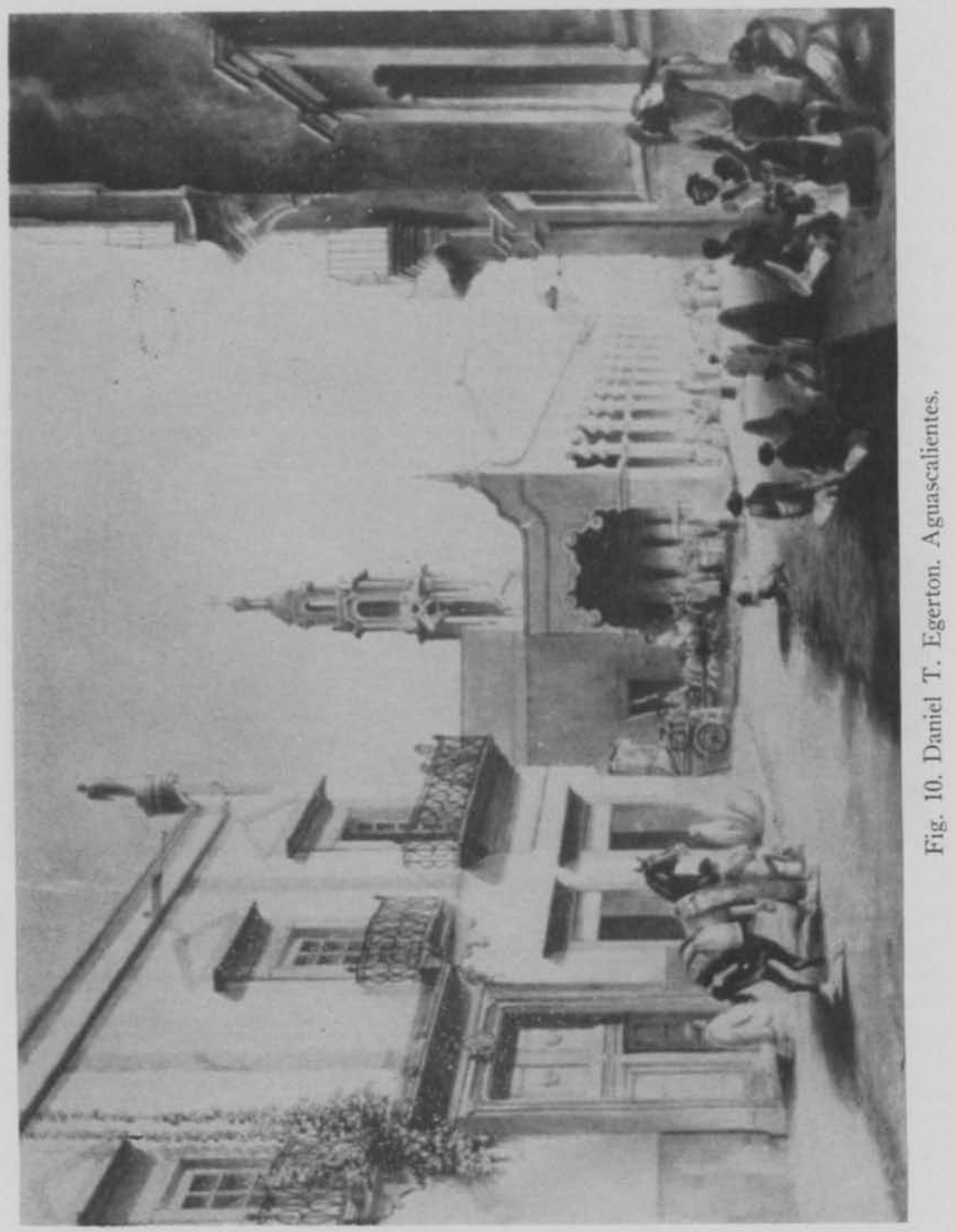




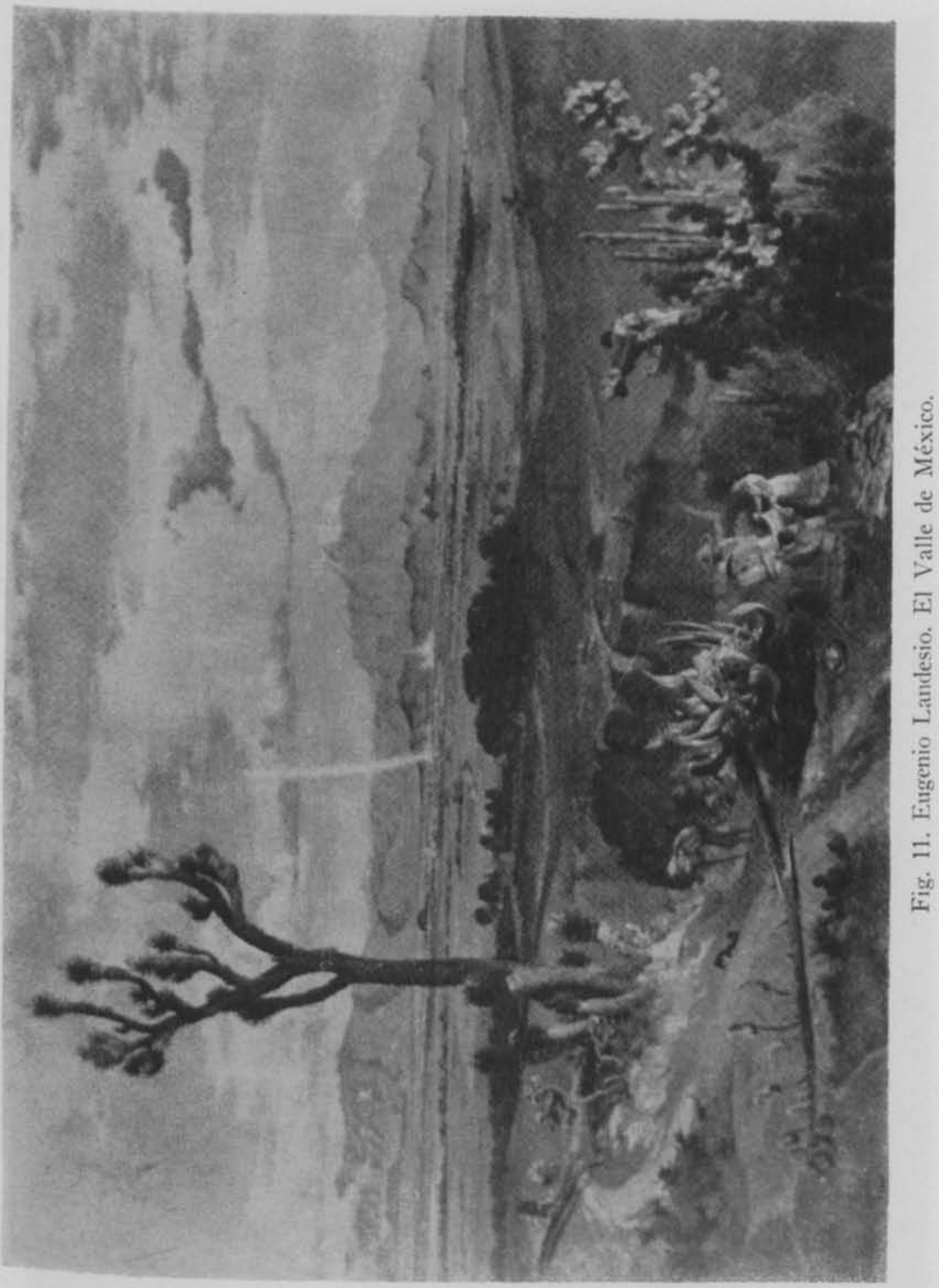


DOI: http://dx.doi.org/10.22201/iie.18703062e.1959.28.668

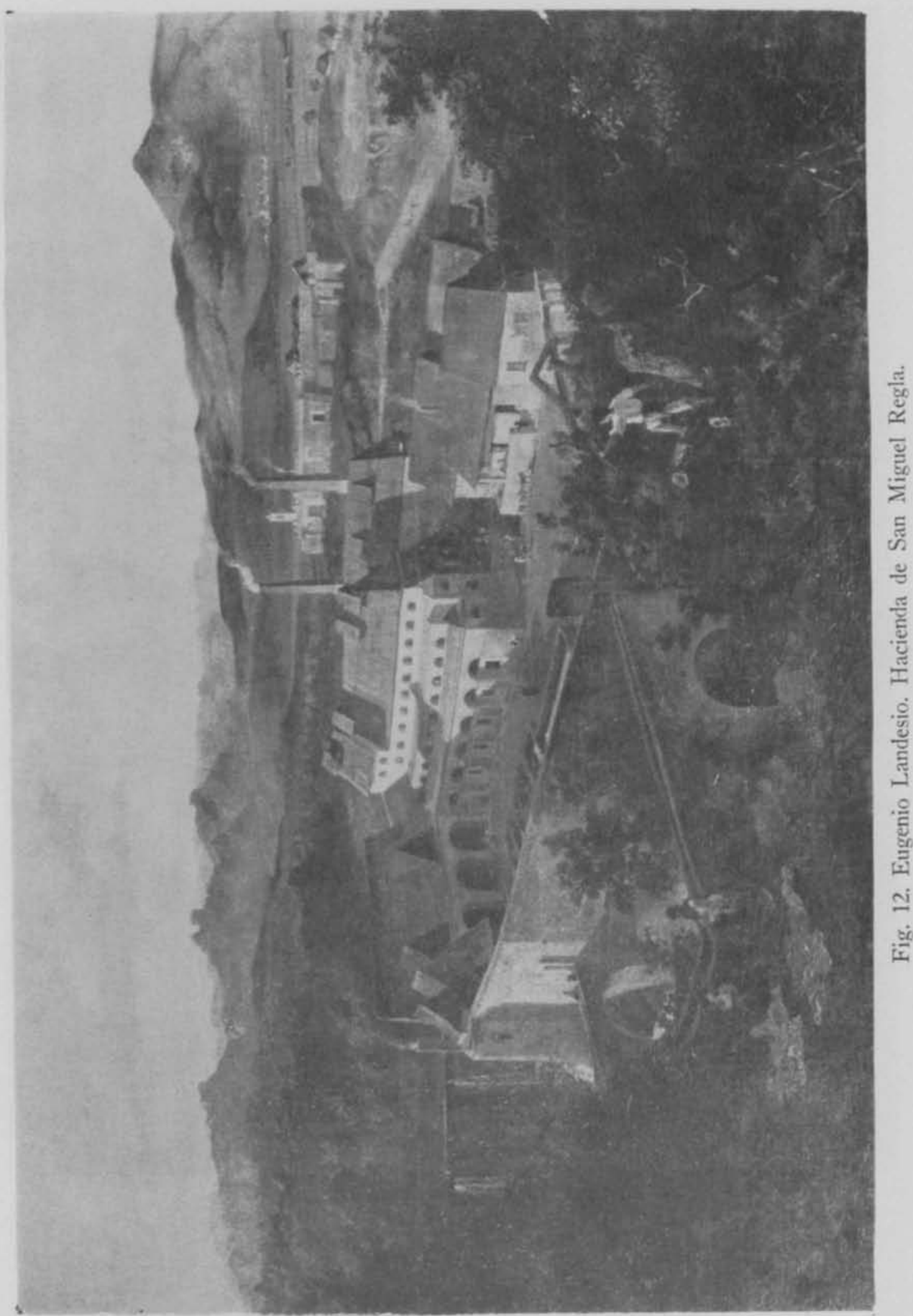


DOI: http://dx.doi.org/10.22201/iie.18703062e.1959.28.668

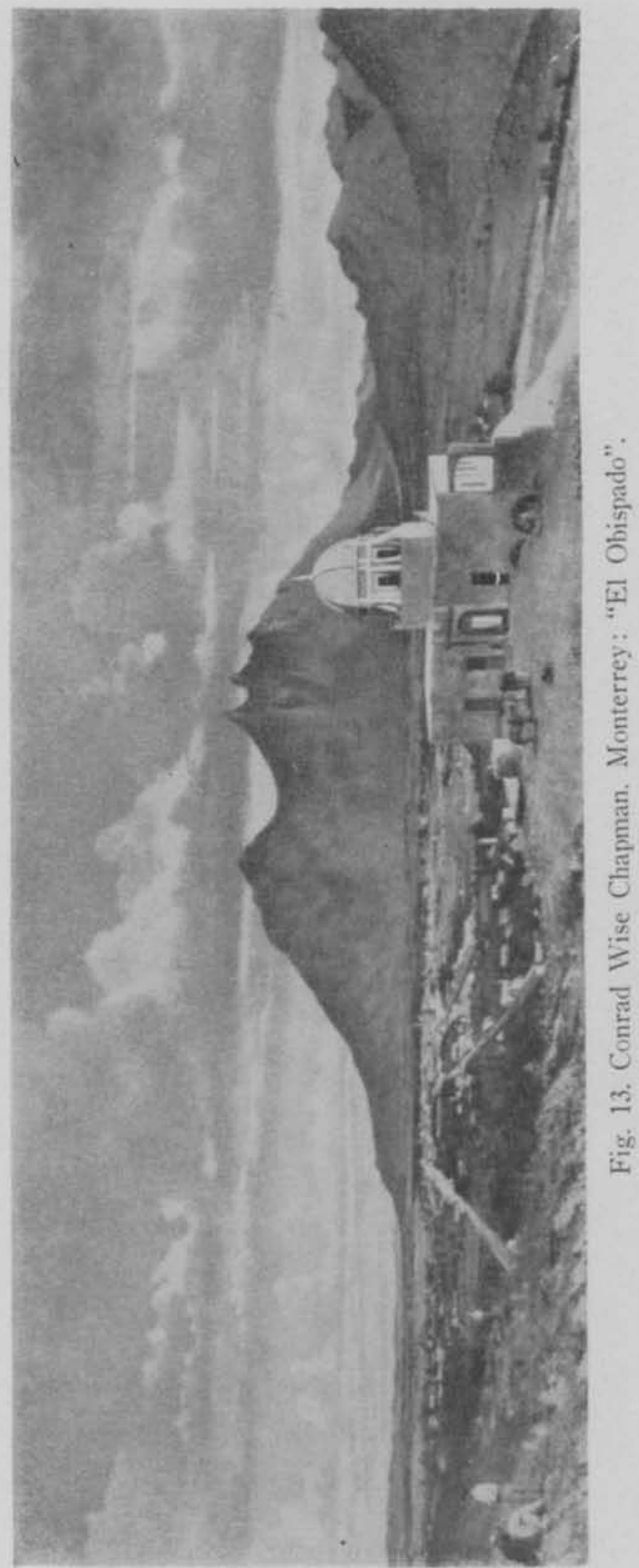


DOI: http://dx.doi.org/10.22201/iie.18703062e.1959.28.668

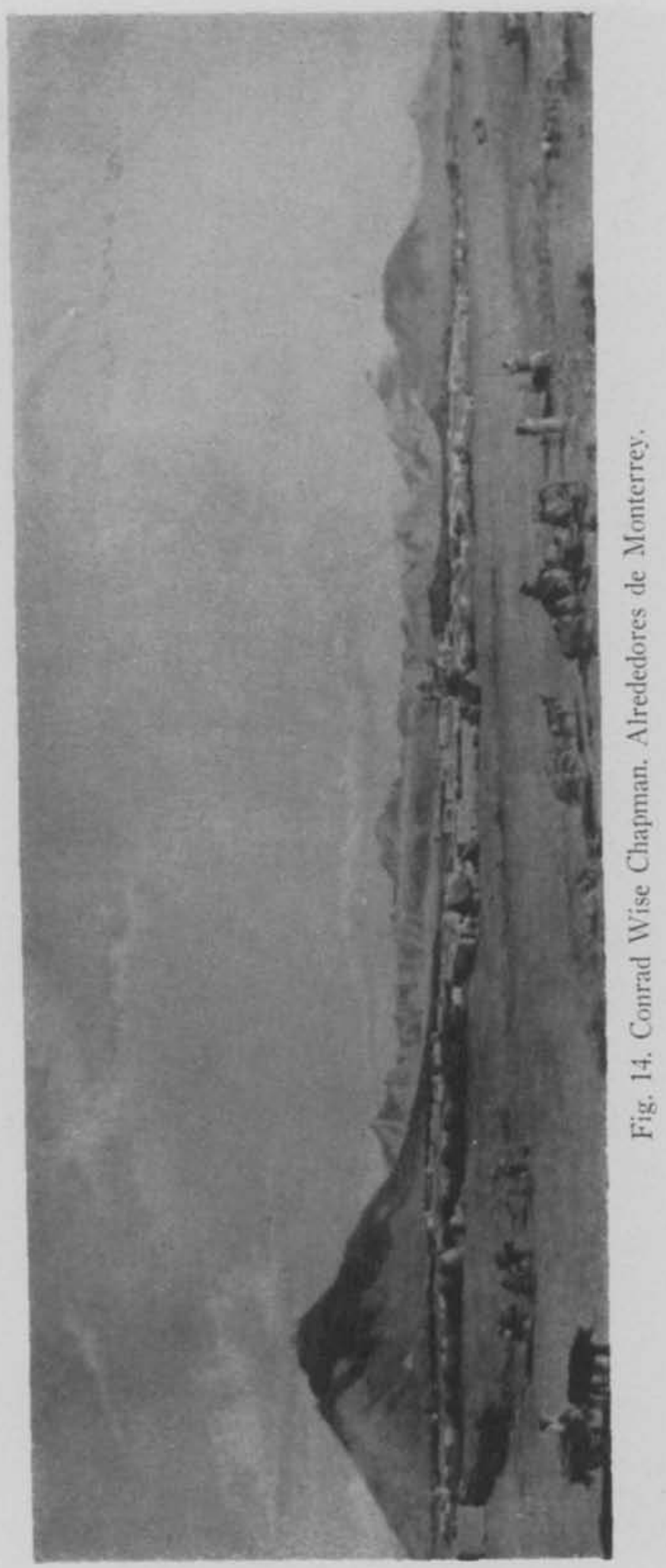


DOI: http://dx.doi.org/10.22201/iie.18703062e.1959.28.668

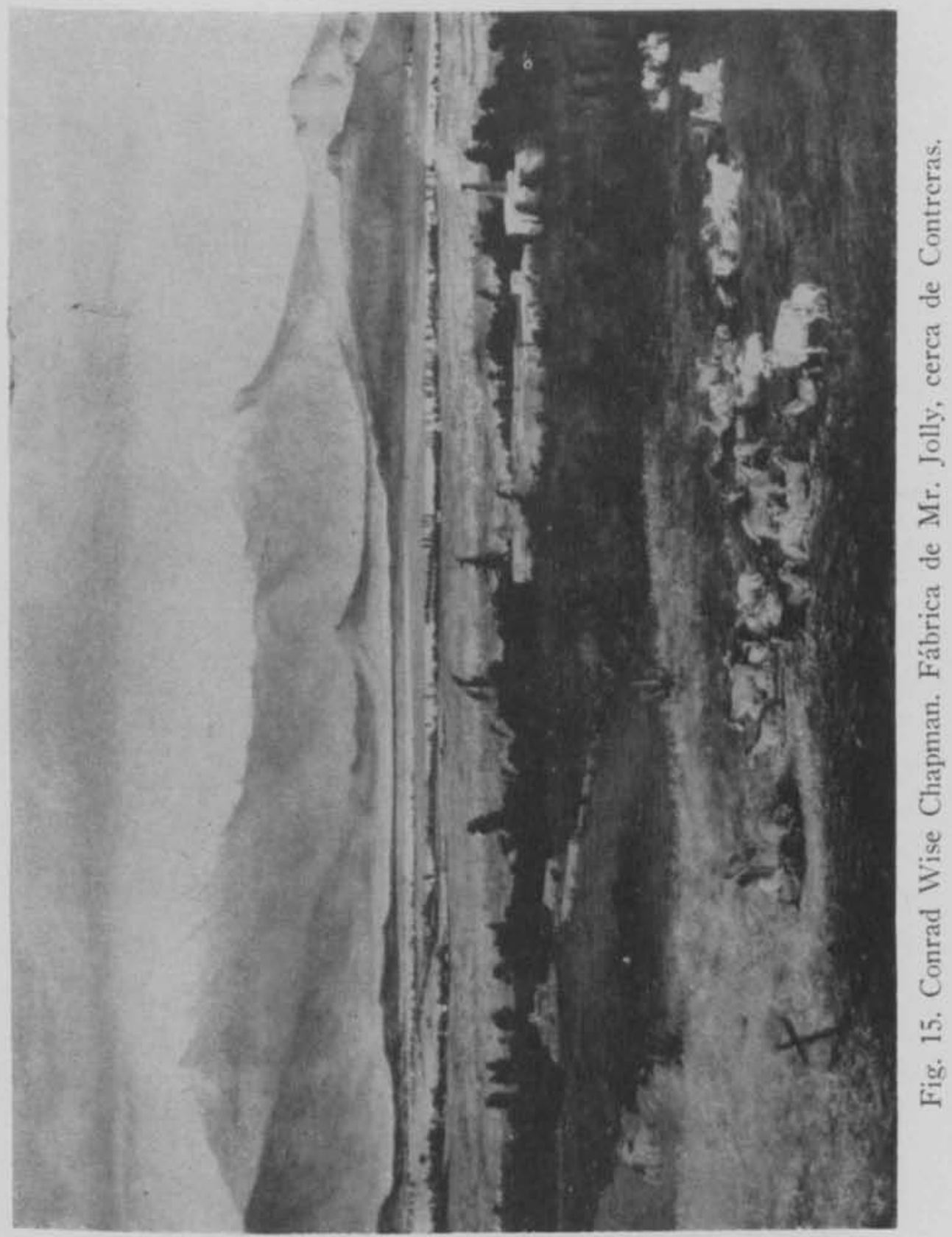


DOI: http://dx.doi.org/10.22201/iie.18703062e.1959.28.668

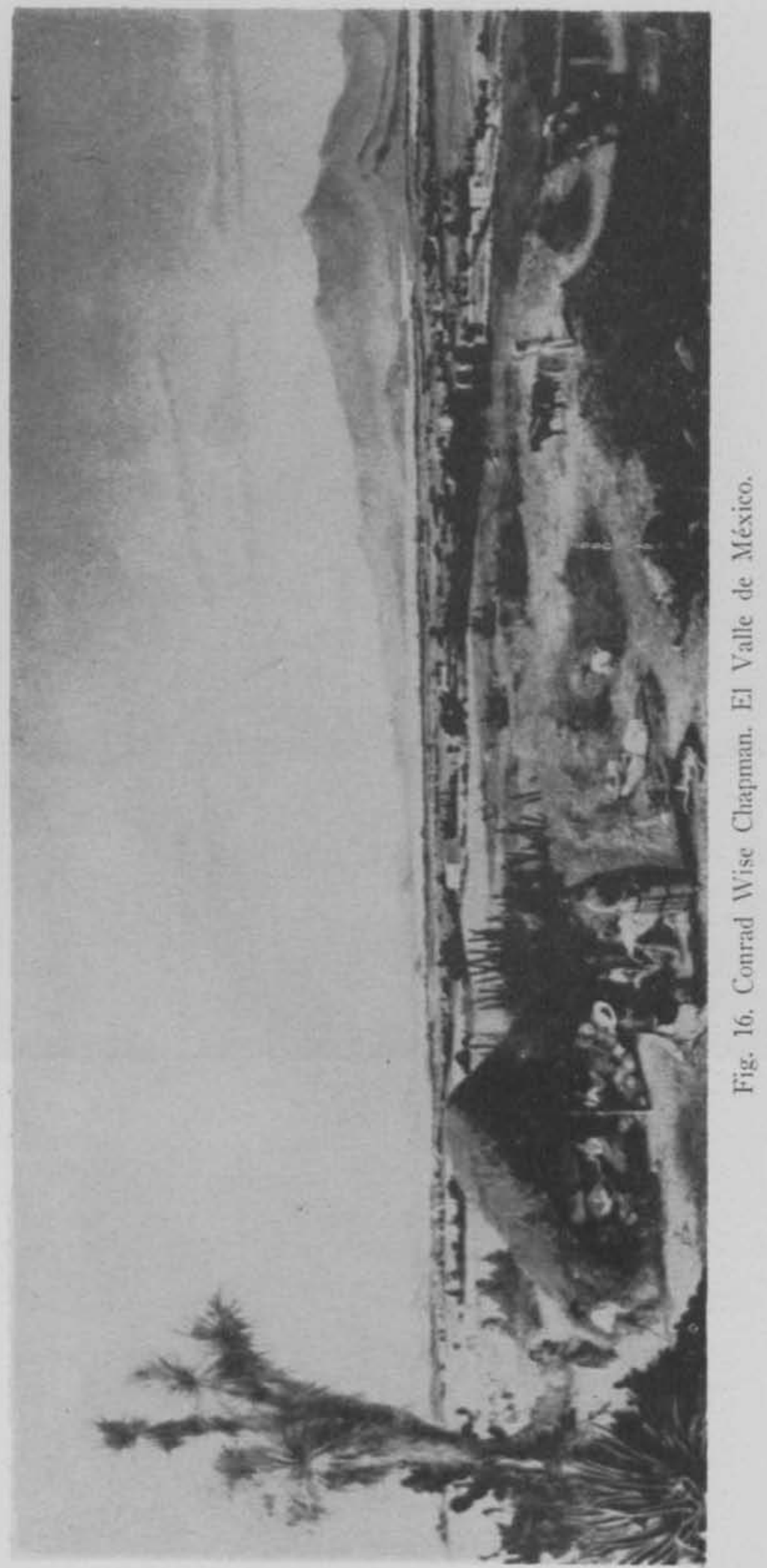




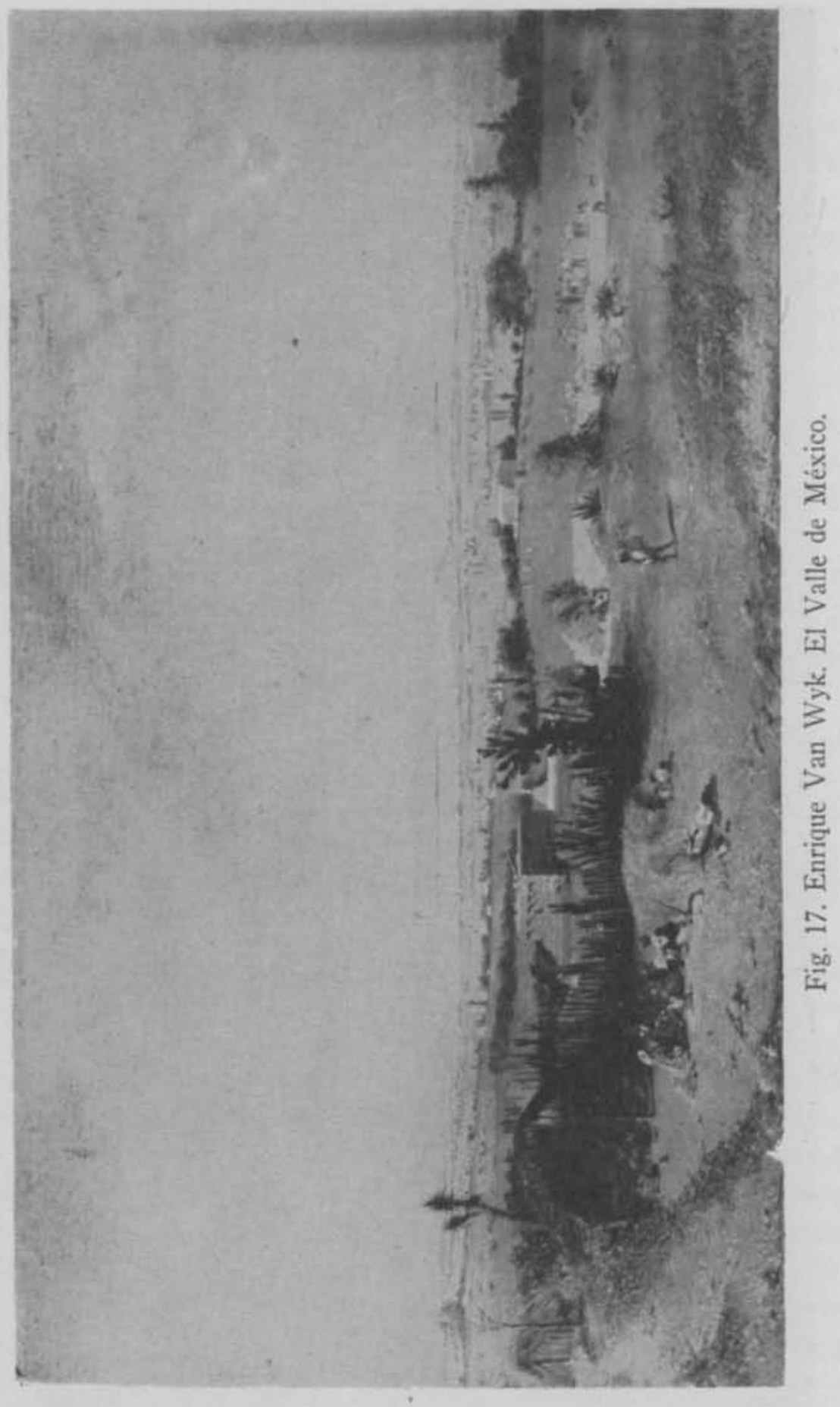




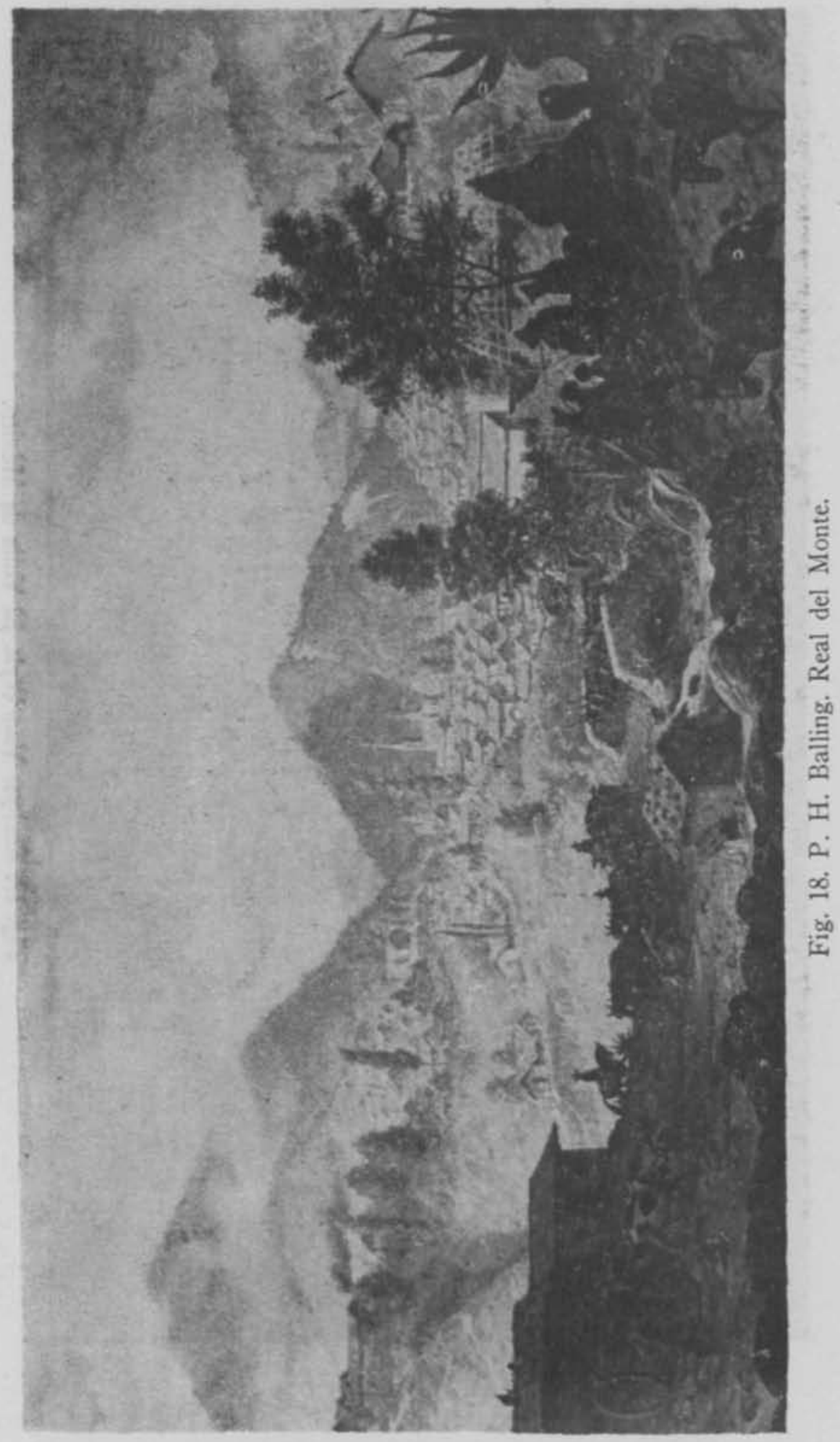


lado de su padre, cuya pobreza lo había obligado a dedicarse al oficio de platero, en el cual quiso iniciar a nuestro artista. Pero tal menester no era de su agrado, y en sus ratos de ocio salía a solazarse al campo, en compañía de su hermano mayor, que había hecho algunos estudios en la Academia de San Lucas, y más tarde logró recibir clase de pintura del paisajista francés Amadeo Bourgeois.

La facilidad con que Landesio sabia dibujar árboles y plantas, lo animaron a publicar, por subscripción; un álbum de litografias, que utilizaron otros artistas y que, si no le produjo ganancias pecumiarias, le atrajo la atención del paisajista húngaro Carlos Markó, residente a la sazón en Roma. Con toda generosidad Markó impartió a Landesio sus enseñanzas $y$, a poco, los cuadros que pintaba nuestro artista, obtenían notable demanda, cosa que le permitió ya vivir de sú arte. Más tarde se le encomendaron obras de importancia, y cuando fue invitado para venir a México, gozaba de justa fama.

Como no hablaba español, se puso a estudiar la lengua y llegó a conocerla a tal grado que, recién llegado a México, pudo escribir en castellano un tratado de perspectiva y, más tarde, una reseña de la enseñanza de su arte entre nosotros.

En la Academia de San Carlos, dictó Landesio las cátedras de paisaje, perspectiva y ornato. Enseñaba a copiar del natural y no autorizaba a sus alumnos a poner colores sobre sus composiciones, sino hasta después de haberse logrado un dibujo perfecto. Tuvo también el mérito de haber sido uno de los primeros pintores de cuadros con asuntos tomados de la historia de México.

Sus paisajes eran de ricas y bien armonizadas tonalidades; animaba sus cuadros con figuras y animales y daba gran ingerencia a los efectos de luz. Se ha tachado su colorido de convencional, pero sus pinturas revelan maestría y gran comprensión de las bellezas naturales de México; aunque debe hacerse notar que nunca olvidó el ambiente de su pais natal, por lo que muchos de sus cuadros mexicanos acusan una tonalidad dorada, que solamente puede llamarse propia de nuestro suelo, en los cortos momentos de la aurora y de la puesta del sol. Enamorado de la naturaleza, Eugenio Landesio relató su excursión a las grutás de Cacahuamilpa y su ascensión al Popocatépetl en un folleto que publicó, en 1868, ilustrado con cuatro litografías de otros tantós cuadros suyos, ejecutadas por su discípulo José María Velasco.

Salió de la Capital, en compañía del escultor Miguel Noreña, en la madrugada del 3 de enero del año citado. Durante el largo e incómodo 
trayecto, y a pesar del brusco movimiento de la diligencia en que viajaba, logró sacar algunos apuntes del Ajusco y sus aledaños, no sin admirar y tomar buena nota de los árboles, frutas y "flores del camino".

La caverna de Cacahuamilpa, como era de esperarse, le causó grande admiración, y la describe de manera clara y detallada, haciendo especial hincapié en los Hlamados "salones del Chivo" y "de la Palmera", que años antes habian cautivado al Barón Gros.

En su camino de regreso pasó por Xochicalco, de cuyas ruinas sacó algunos apuntes, prometiéndose volver más tarde para estudiar debidamente tan importante monumento arqueológico.

La narración de Landesio es amena y sencilla, no sin una que otra nota de humorismo, como cuando describe el asalto que suf rió la diligencia en Topilejo, cuando regresaban de Cuernavaca a la Capital.

La ascensión al Popocatépetl la emprendió en el mes de abril siguiente, en compañía de nuevo de Noreña y de algunos pintores y estudiantes de la Academia de San Carlos. A su paso por Tlalmanalco, llamaron especialmente su atención las ruinas de la capilla abierta del antiguo Convento de aquel lugar, y en Amecameca, el Santuario del Sacro Monte en donde pudo admirar a sus anchas la hermosa vista que desde allí se disfruta.

La ascensión al Popocatépetl la efectuó Landesio en dos etapas, una antes y otra después de pasar en Amecameca la Semana Santa, durante la cual, por cierto, la procesión que presenció el Viernes Santo en el Sacro Monte, le pareció "un buen motivo del género Escenas Populares religiosas, asociado con el de Parques".

En su primer intento no logró el pintor alcanzar la cúspide del "monte que humea"; pero en la segunda ocasión sí llegó hasta el cráter del volcán. En ambos casos, la larga caminata fue ardua y peligrosa, llena de peripecias que Landesio describe minuciosamente, no sin rendir, a cada paso, su acostumbrado culto a Flora y a Pomona. Sacó numerosos apuntes del volcán, entre otros de unas peñas del cráter, "que tenía en su extravagante forma algo de juguetes, pero juguetes diabólicos lanzados del infierno", peñas que reprodujo después en uno de los cuadros que litografió Velasco para ilustrar la interesante relación del pintor.

Don Eugenio Landesio impartió sus enseñanzas en la Academia de San Carlos, como se ha dicho, durante diez y nueve años, pero sufrió durante ese periodo algunos sinsabores, principalmente por cuestiones políticas. 
Abandonó el pais en 1877 y dos años después falleció en París.

La producción pictórica de Landesio en nuestro país fue enorme. Su primer cuadro fue el del puente detrás de la pequeña iglesia de San Antonio Chimalistac (Panzacola); pero su alma de artista fue cautivada, más que nada por el Valle de México, que pintó en varias ocasiones. El que ejecutó para don Enrique Gibbon, ${ }^{1}$ gustó tanto que tuvo que repetirlo, con ligeras variantes, primero para un "señor Lloyd", y luego para Mr. W. R. Jolly (Fig. 11).

En los Catálogos de las Exposiciones de la Academia de San Carlos, Landesio solia describir minuciosamente todas las obras que exhibía, como para hacer ver al espectador hasta el último detalle del cuadro y transmitirle, sin sentirlo, las emociones que lo habían embargado al pintarlo. ${ }^{2}$

Magnifica fue la serie de paisajes del pintor italiano, que podemos llamar de Real del Monte, porque trasladó al lienzo numerosos lugares de aquella pintoresca comarca; las Haciendas de beneficio de Velasco, San Miguel (Fig. 12), Santa María de Regla, y el Aviadero; así como las montañas y cascadas de los alrededores que cayeron bajo la magia de su pincel. Otras fincas de campo fueron también magistralmente pintadas por Landesio, como las de Matlala y Colón, en el Estado de Puebla.

\section{$\mathbf{X I}$}

Cuando terminó la guerra de secesión en los Estados Unidos, muchos de los vencidos "confederados", no quisieron regresar a sus hogares y decidieron ofrecer sus servicios al Emperador Maximiliano. Entre ellos venía el pintor norteamericano Conrad Wise Chapman. Pero el grupo pronto se disgregó y Chapman se encontró en país extraño sin más recursos para vivir que los que le producía su pincel. Ejerció su arte tanto en la Capital, como en Monterrey, en donde ejecutó dos magníficos paisajes de los alrededores de aquella ciudad, en los que se divisan el Obispado y el famoso "cerro de la silla". (Figs. 13 y 14.)

Durante su estancia en México, conoció Chapman a un Mr. Jolly, inglés, que acababa de construir una fábrica cerca de San Angel y quería

1 Con este cuadro de Landesio fue obsequiado el Secretario de Estado, Mr. Elihu Root, en su visita oficial a México en 1907.

2 En esto lo imitaron sus principales discípulos. 
llevar consigo una vista de ella a Inglaterra. Hicieron, pues, él y Chapman, una excursión a la falda del Ajusco para escoger el mejor punto de vista para el cuadro. El joven pintor quedó prendado del panorama que presentaba el valle de México, y desde luego concibió la idea de pintar un gran cuadro de él, y no solamente de los aledaños de la fábrica. En consecuencia, decidió ejecutar un estudio preliminar con la mira de reproducirlo después en mayor tamaño, estudio que se conserva actualmente en el Museo Valentine de Richmond, Virginia, y está firmado y fechado en San Angel, el 29 de mayo de 1866. Es un larguísimo paisaje que abarca desde los cerros de Guadalupe, a la izquierda, hasta Contreras, a la derecha.

Para su cuadro definitivo, Chapman adoptó una tela de las extraordinarias dimensiones de cuatro pies de alto por catorce de largo; y solamente pudo llevar a cabo tan enorme pintura "bajo la cúpula de una iglesia que había sido secularizada (sic) por la Revolución", según afirma Mr. James Ford.

Pero al fin de cuentas, cuadro de tal tamaño no fue del agrado de Mr. Jolly, cuando éste lo recibió en su casa de Manchester, la cual, seguramente, no tenía muro bastante grande en donde colgarlo; y como a él solamente le interesaba la parte extrema derecha de la pintura, en donde estaba representada su fábrica, decidió mandarla cortar, para formar con esa sección un cuadro menor, es decir, de treinta y dos pulgadas de alto por cuarenta y cuatro de ancho (Fig. 15); y el resto de la tela, enrollado, lo relegó a una bodega. Así quedó ignorado su paradero durante largos años, hasta que en el de 1955, la casa M. Newman, Ltd., de Londres, después de numerosas pesquisas se puso al habla con un nieto de $\mathrm{Mr}$. Jolly y, al cabo de diligentes búsquedas dieron con "tres pedazos de tela vieja" abandonados en una guardilla de su casa, los cuales resultaron ser nada menos que el resto del enorme cuadro que habia pintado Chapman. El pésimo estado en que los trozos se encontraban hizo necesaria una larga y cuidadosa restauración, hasta reintegrarlos en un magnifico cuadro (distinto del de la fábrica), que mide cuatro pies, seis pulgadas de largo. (Fig. 16.)

Ahora bien, existe en una colección particular, una pequeña pintura, que a primera vista, presenta extraordinaria semejanza con la tela mayor de Chapman. Ejecutada al óleo en una tabla que mide únicamente veintidós centímetros de alto, por cuarenta y uno de ancho, lleva la firma de Van Wyk y, al dorso, un letrero que dice: Ville de Mexico. 
Enrique Van Wyk, nacido en Amsterdam a fines de 1833, fue un pintor de género que ejecutó varios cuadros, entre ellos, uno que se exhibe en el Museo de Soissons y representa una hostería en tiempo de Luis XIIr. Se ignora la fecha exacta de su venida a México; quizás haya formado parte del llamado séquito belga de Maximiliano. Las reducidas dimensiones del cuadro que nos ocupa lo convierten en una verdadera miniatura, cuyo mérito principal consiste en la minuciosa representación de las numerosas figuras humanas y de animales que lo pueblan. Es una vista tomada desde algún punto de la falda del Ajusco, y su colorido tal vez no sea muy fiel a la realidad, debido a una entonación rosada que no parece muy propia de nuestra atmósfera. En cambio, los varios grupos de figuras que animan la escena son una fidelísima representación de tipos nacionales, ocupados unos en faenas del campo, otros en humildes quehaceres domésticos, mientras algunos más conversan o descansan plácidamente. Medio centenar de estas figuras de hombres y mujeres, varios perros, y seis caballos que trillan en una era, acreditan a Van Wyk como verdadero pintor del género, a la vez que como maestro en el difícil arte de la miniatura. (Fig. 17.)

La semejanza principal del enorme cuadro de Chapman con el pequeñisimo de Van Wyk, estriba en numerosos detalles, tales como la choza que se ve a la izquierda en ambas pinturas, las figuras dentro y fuera de ella, en grupos o aisladas, los "órganos", la palmera y otros más. La semejanza a que aludimos da pie para que, a primera vista, pareciera la pintura pequeña un boceto de la grande; pero, una vez examinada aquella detenidamente, encontramos que, la técnica de Van Wyk es completamente distinta de la de Chapman y que el perfecto acabado de la miniatura, y varios otros pormenores, llevan a la conclusión de que ambos óleos no pueden haber sido de la misma mano.

Aventuramos, por lo tanto, la opinión de que el holandés y el americano contrajeron estrecha amistad y que a veces pintaban juntos (como años antes lo habían hecho el inglés Egerton y el francés Barón Gros), y que en alguna ocasión, acompañanda a Chapman, se le antojara a Van Wyk pintar el mismo paisaje que emprendía el americano, pero como no era posible que ambos terminaran su respectiva obra "de una sentada", durante varios días, mientras Chapman acudia a la iglesia abandonada, y desarrollaba en su enorme cuadro, más o menos de memoria, los apuntes que en el campo había tomado, Van Wyk, podía llevar consigo su pequeña tabla al sitio que los dos habían escogido, hasta terminar, con las consebidas licencias pictóricas, lo que no vacilamos en llamar preciosa miniatura. 
Para terminar, mencionaremos al noruego P. H. Balling, pintor de larga vida puesto que nació en 1823 y murió en 1906. Estudió pintura en París y se aficionó también a la fotografía. Estuvo en varias ocasiones en los Estados Unidos y, en 1891, en México, en donde ejecutó un óleo sobre tela, de un metro cincuenta y dos centímetros de largo por ochenta centímetros de alto que representa un paisaje en el Real del Monte y tiene la particularidad de estar pintado únicamente en tonos grises. (Fig. 18.) Tan interesante "grisaille" reprodujo el campo, la vegetación, las chozas, las figuras y los animales de aquella comarca, con extraordinaria fidelidad, y constituyó, a nuestro parecer, un cuadro único en su género.

\section{O N S U L T A S}

Bernard Denvir. Nineteenth Century Mexican Art. En "The Connoiseur". Londres, mayo de 1955.

Justino Fernindez. Una pintura desconocida de la Plaza Mayor de México. En "Anales del Instituto de Investigaciones Estéticas". N* 17. México, 1949.

James Foro. Chapman. En "Gazette des Beaux Arts". New York, 1942.

Federico Herníndez Serraxo. Jman Moritz Rugendas y su Colección de pinturas costumbristas. México, 1947.

EUGenio LANDESIO. Excursión a la caverna de Cacahwamilpa y ascenwión al cráter del Popocatépetl. México, 1868.

Mantuel G. Revnan. Eugenio Landesio. En "Biografías". México, 1908.

Manuel Romero de Terreros. Un paisajista desconocido. En "Apostillas Históricas". México, 1945.

—. Un pintor francés en México. En "Siluetas de antaño". México, 1937.

- Paisajes mexicanos de un pintor inglés. México, 1949.

- El Barón Gros y sus vistas de México. México, 1953.

___ Atlastla y Popocatépetl. En "Universidad de México". Junio de 1956.

C. Sartorius. México, Landscapes and Popular Sketches. London, 1859. 